\title{
THE DISPLACEMENT METHOD OF WEIGHING LIVING AQUATIC ORGANISMS
}

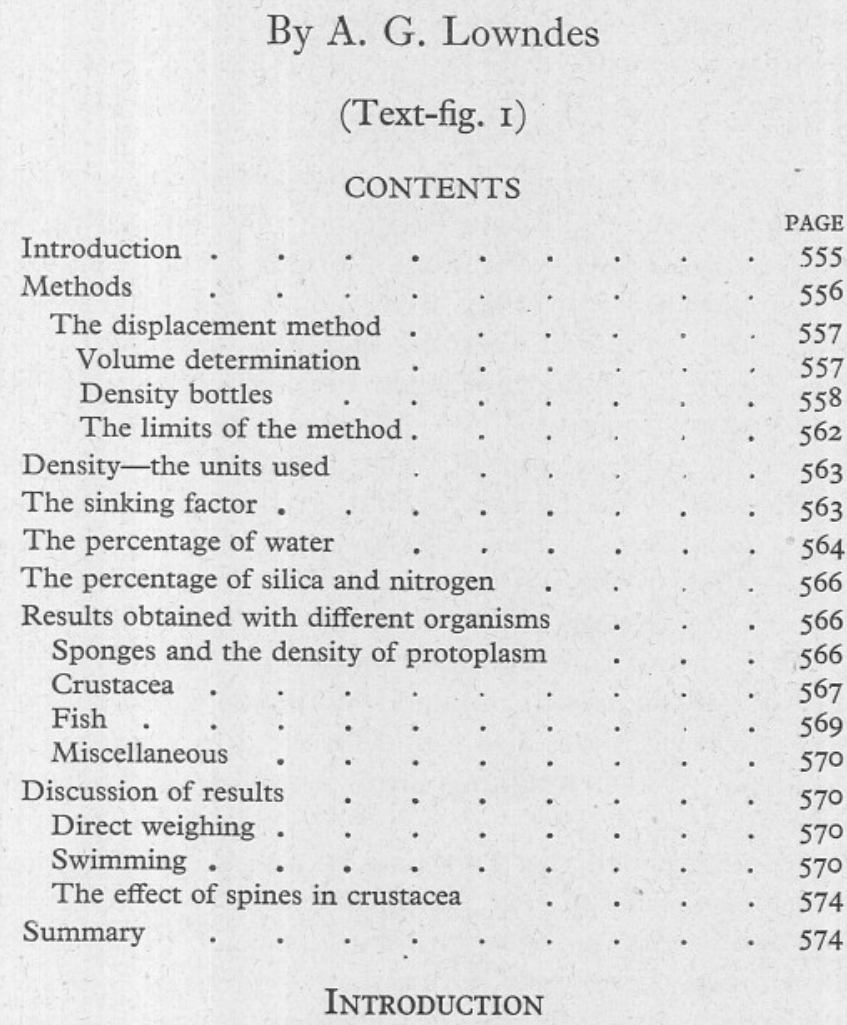

The work to be described constitutes the first successful attempt to weigh a living aquatic organism such as a fish, a prawn or an embryo without removing it from its aquatic environment. My primary object has been to find the density of living aquatic organisms, and this has been done throughout; but since it is essential to weigh before any form of quantitative analysis can be made, it would appear that this is the more basic problem. The determination of the density has as its final goal the problem of the distribution and the amount of energy required for that distribution, while the technique of weighing a living aquatic organism is fundamental in biochemistry and embryology and many other branches of biology.

The work was first started in 1936 , but it was not till 1938 that I was able to give my whole time to it at the Plymouth Laboratory. For this work I received a generous Government grant through the Royal Society, together with 
a similar grant from the British Association, and I am indebted to the Marine Biological Association for laboratory accommodation and all possible facilities. To all these bodies I wish to express my gratitude.

The war has brought many and serious interruptions to the work, and though in normal circumstances publication at this stage might well be thought premature, it has been thought best in existing conditions to give an account of the results so far obtained.

\section{MetHods}

To find the density of an organism it is necessary to weigh it and to find its volume, and since many people have suggested that this can be done directly it is thought advisable to discuss the method briefly. A large prawn was known to weigh $5.253 \mathrm{~g}$. with an error of less than $\pm 0.007 \mathrm{~g}$. It was weighed directly by placing it in a dry stoppered weighing tube and weighing the whole. Then the prawn was removed and the tube again weighed. The weight was found to be $5.663 \mathrm{~g}$., indicating an error of $8 \%$. The volume of the same prawn was known to be $4.80 \mathrm{ml}$. with an error of rather less than $\pm 0.010 \mathrm{ml}$. Its volume was obtained directly by taking two $100 \mathrm{ml}$. graduated cylinders and rinsing them both with sea water. One was filled with sea water, the prawn inserted and the water levelled to the $100 \mathrm{ml}$. mark. The water was then poured into the other cylinder leaving the prawn behind, and it was drained for $15 \mathrm{sec}$. The volume of the prawn thus obtained was $6.0 \mathrm{ml}$., thus indicating an error of $24 \%$. In nearly all the results obtained by the displacement method (to be described later) the weight was also found by the direct method and the percentage error given. Direct weighing forms a useful check, but for accurate work it is useless.

It has also been suggested that a fish can be weighed by weighing a tank of water and dropping the fish into it, but apart from the fact that it is not possible to dry the fish, or even to drain it properly without bringing about serious physiological changes, there is the difficulty of weighing a tank of water. The accuracy with which anything can be weighed depends primarily on the earth's gravitational constant, and it can be shown on theoretical grounds that the extreme limit is I part per $1,000,000$. Thus it is not possible to weigh a kilogram to the fourth decimal place of a gram. In practice the seventh figure in any single weighing is meaningless. If a tank holding 101 . of water is taken, and this amount is certainly not sufficient to cover a large dogfish, a lobster or a crab, a weight of nearly $20 \mathrm{~kg}$. has to be dealt with, and since the displacement value of the majority of organisms in sea water is quite small, the difference in weight cannot be measured by direct weighing with reasonable success. Similarly, since a measuring cylinder always carries Ioo divisions unless it is specially made, a litre cylinder having a diameter of about 3 in. will only read to Io ml. A measuring cylinder which would take a large crab some Io in. in length of carapace could only be read to about $100 \mathrm{ml}$. The above difficulties should be sufficient to indicate that a special technique is essential. 


\section{The Displacement Method}

The general principle of the method I have adopted lies in the use of the specific gravity or density bottle, which is probably the most accurate of all volumetric apparatus. The bottle is weighed full, the animal inserted and the bottle again weighed. There is almost without exception an increase in weight, showing that all marine organisms have a density greater than that of sea water. The method can, however, only be rendered strictly quantitative if it is possible to obtain the volume of the organism and the density of the sea water together with the volume of the density bottle. The last two are easily obtained by standard methods and present no great difficulty. The important point is the accurate determination of the volume of the organism.

Volume Determination. If a density bottle is filled with sea water and the contents poured into excess of silver nitrate, a definite weight of silver chloride or rather silver halide is obtained. This precipitate can be weighed, and one is actually using what is probably the most accurate of all gravimetric determinations in standard analytical chemistry. If now the same bottle is again filled with sea water, a shrimp inserted, and the water again poured into excess of silver nitrate, a smaller weight of silver halide will be obtained. From these two weights it is possible to obtain the volume of the shrimp with extreme accuracy; but there is, however, the rinsing of the shrimp to be taken into account. In the first instance the bottle was rinsed with distilled water; but this cannot be used for rinsing the shrimp because of the difference in osmotic pressure between it and sea water. The shrimp must therefore be rinsed with a solution devoid of halide but having the same osmotic pressure as sea water. The obvious washing or rinsing solution is one of sodium nitrate to which a little calcium nitrate is added. In practice the shrimp is retained on a filter and rinsed quickly with the isotonic solution. The volume of the shrimp having been determined, its weight and density can be obtained and the shrimp can go back to the aquarium for further experimental work. An animal tissue would naturally be weighed in a suitable Ringer solution, otherwise the procedure is identical.

In actual practice the technique is rather laborious and less simple than it sounds at first. It consists, however, in the preparation of the isotonic solution of sodium nitrate and the making and standardization of suitable density bottles. Dealing with the solution first: $4 \mathrm{lb}$. of pure sodium nitrate are dissolved in about 81 . of water. I00 $\mathrm{ml}$. of pure nitric acid are neutralized with excess of calcium carbonate and the solution boiled and filtered into the sodium nitrate solution. The $p \mathrm{H}$ is brought up to that of sea water by adding a dilute solution of sodium carbonate. In practice this neutralization is quite easy, for on adding the sodium carbonate a precipitate is formed which dissolves less and less readily as one approaches the end-point. The freezing-point of the solution is determined accurately with the Beckman apparatus at different concentrations and a convenient table constructed. It is found that if $350 \mathrm{ml}$. 
of the above solution are made up to a litre, a solution very slightly hypertonic to the Plymouth circulation sea water is obtained.

In dealing with organisms living in brackish water the freezing-point of the environment must first be ascertained and then the corresponding solution of nitrate made up. The solution should be as near isotonic with that of the environment as possible, but it should be hypertonic rather than hypotonic, for if the nitrate solution is hypotonic the organism will take in water and give out chlorides, while if it is hypertonic it will give out water, which will make no difference to the measurement of the volume at this stage, and the rate at which the organism will absorb chlorides will be so slow as to be negligible, apart from the fact that there is very little chloride available for it to absorb. It should also be remembered that the nitrate solution need only be in contact with the organism for a very short time, usually a few seconds or half a minute at the most. The bivalent calcium ion has the effect of slowing down the rate of exchange of ions considerably.

That this nitrate solution has no detrimental effect on the organisms is shown by the fact that they will survive being placed in it many times in succession. Thus the same specimen of the first larva of a lobster has been rinsed thoroughly in the solution six times during the one day. The same is true for Anemonia sulcata and for the sponge Ficulina ficus. If a young nursehound is removed from sea water, it soon forms within the pharynx quantities of mucus, but nothing of the kind appears when it is immersed in the nitrate solution.

Density Bottles. The greatest difficulties in the displacement method are those afforded by the density bottles. While it is easy to clean and dry a crucible and handle it with forceps, and finally leave it on the balance for some time before weighing, such things cannot be done with a density bottle containing a liquid, and the difficulty becomes far greater if the bottle contains a living organism which is to survive. The accuracy of the method is determined by the consistency of consecutive readings with a bottle which is filled, dried on the outside and placed on the balance. If the difference does not lie within a milligram it is clearly useless to weigh to the fourth decimal place. The difficulty has been long recognized and partly overcome by such devices as the Bousfield and Sprengel pycnometers; but these are useless for weighing anything but the very smallest organisms by the displacement method. If a IOO $\mathrm{ml}$. density bottle when full of sea water can be weighed accurately to within a milligram the percentage error is small; but we are concerned with the displacement weight, or the difference between the bottle full and the bottle with the organism inserted, and since this seldom amounts to more than a few grams the percentage error may be considerable.

The density bottles used range from those holding $0.5 \mathrm{ml}$. to those holding nearly 81 . The smaller bottles, which are always of the type shown in the diagram (Fig. I $a$ ), are always placed for weighing in a close-fitting outer covering (Fig. $\mathrm{I} b$ ). The water evaporating from the bottle itself quickly saturates the relatively small space enclosed, while the rate of diffusion be- 
tween the air in the outer case and the desiccated atmosphere of the balance itself is extremely slow. A density bottle of this type, placed in its outer case, showed no increase or decrease in weight at the end of half an hour on the most sensitive balance used. The outer case need never be removed from the balance case. Usually a reasonably accurate weighing can be made with one of these smaller bottles in $30 \mathrm{sec}$. at the most. The balances used with bottles up to Ioo $\mathrm{ml}$. are the air-damped Sartorious type or the new Oertling aperiodic type, or in the smallest bottles a Sartorious air-damped microbalance, these balances carrying a maximum load of 200, I00 and $20 \mathrm{~g}$. respectively with corresponding sensitivities.

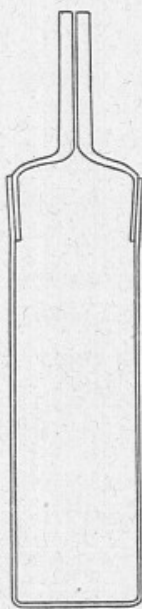

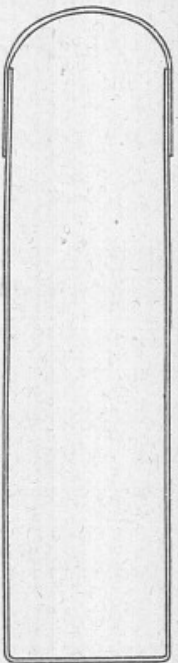

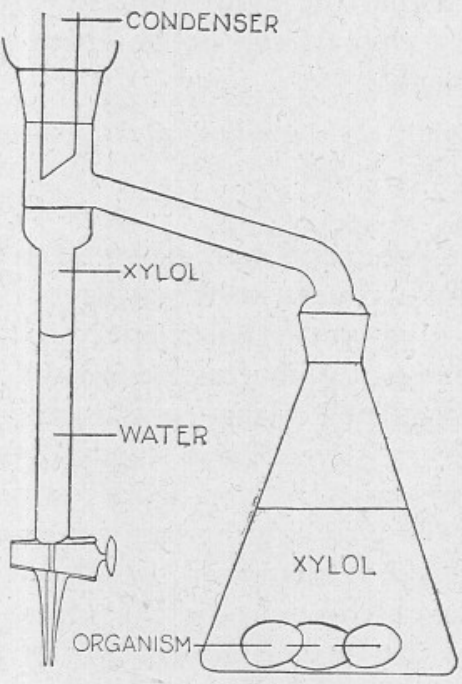

c

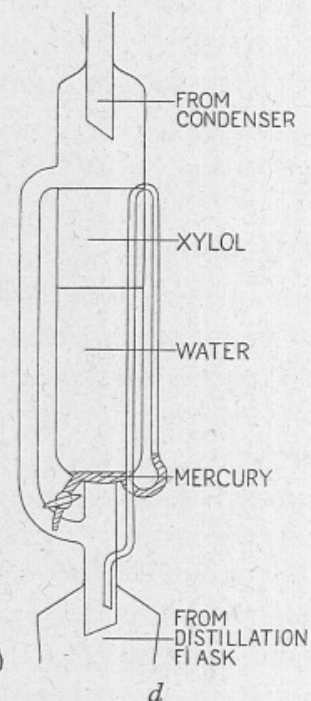

d

Fig. I. $a$, type of density bottle used. $b$, outer case for taking the density bottle while being weighed. c, an ordinary Dean \& Stark's apparatus used for the estimation of water. $d$, an ordinary Soxhlet Extractor used as a Dean \& Stark's tube. The siphon tube is blocked with a little mercury. Water collects in the extractor and xylol automatically returns to the distillation flask.

For the weighing of prawns a special density bottle was made. Some long thin weighing bottles were found in the laboratory. They were just over 4 in. long and fitted with a good ground-glass stopper. A small $\mathbf{V}$ notch was made in the stopper with a file and the bottle carefully standardized by use of N.P.L. tables. It was easy to make up a closely fitting outer case. The volume of the bottle was about $35 \mathrm{ml}$, and since $\mathrm{I} \mathrm{ml}$. of sea water gives about $0.08 \mathrm{~g}$. of silver halide precipitate, the whole contents of the bottle gave about $2.8 \mathrm{~g}$. of the silver salt. This amount of silver salt is easily handled with modern sinter glass crucibles and can be weighed accurately. The limit of accuracy here is clearly the accuracy with which the bottle can be dried and weighed consistently. The only real test is the error obtained by taking the same prawn, 
weighing it several times and comparing the result; but unfortunately this is not so simple as it sounds. No living aquatic animal is unaffected by handling, and in prawns scales or spines may be lost or the animal may excrete or feed during the process. Moreover, the aerated sea water frequently gives off bubbles of air and these may seriously affect the result. It is true that the air could be expelled from the sea water by first boiling it, but the animals are not living in freshly boiled sea water.

The following table shows the extremes obtained by weighing the same prawn four times by the displacement method and thus obtaining the extremes of weight, volume, density and sinking factor (the last-named is described later). It will be seen that the figures for the last two agree well to within I part per 10,000, and this appears to be about the limit of accuracy for a very favourable organism.

$\begin{array}{ccccc}\text { Volume ml. } & \text { Weight g. } & \text { Density } 15.2^{\circ} \mathrm{C} \text {. } & \text { Sinking factor } & \% \text { error in volume } \\ 4.8 \mathrm{IO} & 5.2597 & \mathrm{I} .0935 & 1066.2 & 0.026 \\ 4.795 & 5.2438 & \mathrm{I} .0936 & 1066.3 & 0.026\end{array}$

While the above measurements were being taken the prawn in question shed one of its uropods; this accounts for the difference in weight and volume, but as might be expected it has not seriously affected the density or sinking factor.

Apart from the expense, it is not feasible to work with a much greater weight of silver halide than that used in this experiment; if a larger density bottle is used, its contents are transferred to a standard flask, a suitable volume extracted with a pipette and the silver halide estimated gravimetrically, or in certain cases by titration. The limiting factor in this method is the accuracy of the pipette, which increases the error considerably, and if one resorts to a titration the percentage error may be considerable. The same prawn was again weighed by the displacement method, but a titration was substituted for a gravimetric estimation. This gave the following result:

Volume ml. $4 \cdot 717$
Weight $\mathrm{g}$. $5 \cdot 1664$

Density $15 \cdot 2^{\circ} \mathrm{C}$ I.095

Sinking factor I068.0

$\%$ error in volume

From the above figures it will be seen that a titration is scarcely satisfactory, but much depends on what proportion of the volume of the density bottle is occupied by the organism. An example will make this clear. A full-sized prawn in berry will just go into an ordinary $\frac{3}{4}$ in. test-tube and occupy about three-quarters of the length. The volume of the test-tube level with the tip of the rostrum of the prawn is about $35 \mathrm{ml}$., but the volume of the prawn itself is only $5 \mathrm{ml}$. If the sea water from the test-tube is poured into a $250 \mathrm{ml}$. flask, in the one case $35 \mathrm{ml}$. of sea water will be added and in the other $30 \mathrm{ml}$., and the difference in these two solutions is too small to be estimated with any great degree of accuracy. The actual figures approximate to the following: If a $35 \mathrm{ml}$. density bottle full of sea water is taken and rinsed to fill a $250 \mathrm{ml}$. flask, then $25 \mathrm{ml}$. of this solution will be titrated by $19.6 \mathrm{ml}$. of $\mathrm{N} /$ IO silver nitrate. If the prawn, of an assumed volume of $5 \mathrm{ml}$., is inserted into the density bottle, 
which is again washed out into the same $250 \mathrm{ml}$. flask, $25 \mathrm{ml}$. of this solution will be titrated by $16.8 \mathrm{ml}$. of the silver nitrate. Assuming the accuracy of the titration to be within $\pm 0.02 \mathrm{ml}$. the percentage error is $\frac{0.02 \times 100}{\mathrm{I} 9.6-\mathrm{I} 6.8}=0.7 \mathrm{I}$, and to this must be added a further error of 0.02 due to dilution. If, on the other hand, the solutions are estimated gravimetrically, the figures are as follows: $35 \mathrm{ml}$. of sea water will give $2.8 \mathrm{~g}$. of silver halide while $30 \mathrm{ml}$. will give $2.4 \mathrm{~g}$. These weights can be measured accurately and in practice they will give the fourth place of decimals. The percentage error is therefore $\frac{0.000 I \times I 00}{2 \cdot 8-2.4}=0.025$, and since there is no dilution this will be the total percentage error. Thus gravimetrically the percentage error is 0.025 compared with an error of 0.73 by titration. In practice I have almost entirely discarded titrations in this work.

It might be expected that an even greater degree of accuracy could be obtained as the result of this gravimetric work, but in general this cannot be done. Greater accuracy can only be obtained with such material as the early larvae of crabs or lobsters which can be packed into a density bottle very closely and made to occupy a large proportion of its volume. It must be remembered that the density bottle is used as a piece of volumetric apparatus, and this must put its own limit on the work. A density bottle cannot be graduated to the fifth decimal place of I ml., and it is being used with organisms and not dry chemicals. It should also be borne in mind that sea water itself is not a pure solution of sodium chloride.

For bottles holding over $100 \mathrm{ml}$. a special technique is required and practice has shown that excellent density bottles are easily made by taking good widemouthed bottles with suitable stoppers and cutting a $\mathrm{V}$ notch in the stopper. Excellent bottles for this purpose are made in the following sizes: $8, \mathrm{I} 2, \mathrm{I} 6$, 32 , and $64 \mathrm{oz}$. The $8 \mathrm{oz}$. bottle has an approximate volume of $315 \mathrm{ml}$. and the $64 \mathrm{oz}$. holds nearly 21 . The stopper must be marked so that it can be replaced in exactly the same position each time, and the bottles must be accurately standardized by means of N.P.L. tables. Evaporation from these widemouthed bottles is a difficulty, but for reasons which need not be discussed it is far less in these bottles with a V notch than it is in those bottles with the ordinary perforated stoppers. For weighing with these larger bottles I have used two Oertling balances, the one taking a maximum load of $2 \mathrm{~kg}$. and the other $5 \mathrm{~kg}$. Weighing is here a much slower process, but since the animals are larger and more robust they can remain in one of these bottles for a longer time without suffering any apparent injury. With care the same animal can nearly always be weighed twice. The first time an approximate weighing is obtained; the animal is then returned to circulation for a short time, and on the second weighing an accurate figure is quickly obtained. If necessary, evaporation can be overcome completely by placing the large bottles in an outer covering as recommended for the smaller bottles; well-made tins can 
be used. The disadvantage with the larger bottles is that the contents must be poured into a standard flask and an aliquot part extracted with a pipette, and this naturally limits the accuracy. In practice $50 \mathrm{ml}$. are extracted with the pipette and the silver halide estimated gravimetrically. These larger bottles are admirable for weighing nearly full-sized dogfish.

The work has now been extended so that the largest crabs and lobsters can be weighed, but this has involved a rather special technique. The density bottle presented considerable difficulty, but I was fortunate enough to obtain a large vessel with a really well-fitting stopper, made for the storage of sterilized instruments and dressings. By cutting two $V$ notches in the stopper it was possible to convert it into a good density bottle. It held over $7 \frac{1}{2} 1$. and had a mouth about $8 \mathrm{in}$. across. Two flasks of suitable size had to be obtained, and this presented some difficulty for they had to hold at least Io 1 . The neck of one of them was carefully marked. It was unnecessary to standardize this flask provided there was some means of filling it up to the mark consistently. Finally, a suitable balance had to be obtained, and this was eventually supplied by Messrs Avery and Co., Ltd. It is capable of taking a load of well over $20 \mathrm{~kg}$. and can be read to the nearest gram. The balance has the great advantage of being damped by a special kind of oil-bath and weighings are thus instantaneous.

With practice the jar could be filled and the weight read consistently to within a gram, and since the whole weighed just over Io $\mathrm{kg}$. the error was not more than I in I0,000. This apparatus was only used for the largest animals, and provided the displacement value was over $100 \mathrm{~g}$. the percentage error in weight would be less than $\mathrm{I}$. Since any error in weight affects the weight and volume of the animal in question in the same direction and approximately to the same extent $(\mathrm{I} \cdot 025: \mathrm{I} \cdot 0)$, the density and the sinking factor can be relied upon at least to the fourth digit. Titration would introduce far too great an error to be of any service.

The Limits of the Method. As an upper limit it may be stated that the largest lobsters to be obtained from the ordinary market and almost the largest crabs can be dealt with by the method outlined above. Nursehounds up to a metre long and even still longer congers can also be weighed, but the handling of these animals is difficult. The chief danger is that the large crabs or lobsters may break the jar with their claws. It is, however, the lower limit that is the most important, and in this respect the method is disappointing. The smallest density bottle used holds $0.5 \mathrm{ml}$., and so far I have found it impossible to place it consistently on the balance when full, with an error of less than O.I mg. This is about ten times the displacement value given by ten specimens of Calanus, and it is therefore impossible to weigh a single specimen of the copepod. It is possible, however, to obtain a reasonably accurate figure by placing 100 specimens in the bottle. Similarly, it has not been found possible to weigh satisfactorily a single specimen of the first larva of the lobster. On the other hand, it is quite easy to hatch out the first larvae of a single prawn in 
berry and get a very accurate estimate of the density by weighing several hundreds of them at once.

\section{Density. The Units Used}

By density is meant the mass of unit volume, and the unit of volume is the millilitre and not the cubic centimetre. In all cases the densities have been calculated according to the formula

$$
d_{4^{\circ}}^{\circ}=\frac{W^{\prime} D}{W}-\frac{0.0012\left(W^{\prime}-W\right)}{W} .
$$

$d_{4^{\circ}}^{t^{\circ}}$ means the density of the liquid at $t^{\circ} \mathrm{C}$. compared with that of distilled water at $4^{\circ} \mathrm{C}$. (its maximum density). $W$ is the weight of distilled water at $t^{\circ} \mathrm{C}$. and $W^{\prime}$ is the weight of sea water at the same temperature. The second part of the formula is the correction for the buoyancy of air. The formula is that given in Practical Physical Chemistry by Alexander Findlay (Longmans, London). The density of water at different temperatures is that given on p. 64 of the same book. Owing to the discovery of 'heavy water' the whole concept of pure distilled water has been changed. The distilled water used for standardization of apparatus in this work was obtained by distilling the Plymouth tap water first in an 'Atmos Still' and then redistilling it in a special still of Monax glass.

\section{The Sinking FACTOR}

Little information is conveyed by a determination of the density of the organism unless the density of the environment is determined at the same instant and under the same conditions of temperature. It is usually assumed that the density of sea water is $\mathrm{I} \cdot 03$, but this is scarcely correct for Plymouth sea water, and naturally the density varies with the temperature. What is required is a simple expression which will at once show the relation of the organism to its environment at the time of the determination. As an example: it was found that the density of a certain dogfish at a temperature of $17 \cdot 2^{\circ} \mathrm{C}$. was $\mathrm{I} \cdot 076 \mathrm{I}$, while the density of the environment at the same temperature was $\mathrm{I} \cdot 02552$. The obvious way of comparing these two densities is by means of the ratio $\frac{\text { Density of dogfish }}{\text { Density of the sea water }}$ or $\mathrm{I} \cdot 076 \mathrm{I} / \mathrm{I} \cdot 02552$, which gives $\mathrm{I} \cdot 0493$. This, however, is not an easy number to bear in mind, and it is therefore multiplied by 1000 and the last figure discarded. The sinking factor of the dogfish in question would thus be 1049. A few examples of other results may be given. Only two determinations were made with the conger, and in both it was, impossible to get a displacement value at all; in other words, the density of the fish was that of its environment, and the sinking factor (or S.F.) is therefore 1000. In the common stickleback the factor was found to be 1002, in the dogfish 1049, while in lobsters a sinking factor of II 40 has been obtained. This evidently means that a conger need make no effort to keep itself off the 
bottom; a stickleback requires a little more effort, while a dogfish must exert a much greater effort. Lobsters require a great expenditure of energy to raise themselves off the bottom.

\section{The Percentage of Water}

Previously this was obtained with an organism such as a sponge by taking the sponge and rinsing it quickly in distilled water and drying it either in air, when it would largely decompose, or heating it in an oven at $90^{\circ} \mathrm{C}$., in which case it would take days to acquire a constant weight and give off a good deal besides water and incidentally retain a good deal of its water. Alternatively, it might be dried for weeks in a vacuum desiccator.

The method I now use is a modification of that of Dean \& Stark for finding the percentage of water in oils. The apparatus is quite simple and is of a standard type which can be obtained from any dealer in chemical apparatus. For the smaller animals the apparatus is that figured in the diagram (Fig I $c$ ). Assume for simplicity that one wants to find the percentage of water in some such animal as a mouse or a cockroach, both of which can be weighed on the balance without any appreciable error. The mouse is weighed, for preference in the distilling flask, and then covered with several times its volume of xylol. The whole is then heated over an electric hot-plate, and both xylol and steam are driven off and condensed and fall together into the graduated receiver. The two liquids are not miscible and the xylol floats on top of the water. Xylol distils at a temperature of just over $130^{\circ} \mathrm{C}$., and so a good deal is driven off besides water, but any fats or oils remain in the xylol and do not affect the result. The point at which all the water has been driven off is clearly marked, for so long as water is coming off the xylol floating above the water is cloudy; distillation is therefore continued till a clear layer of xylol forms above the water. In actual practice it seldom takes more than an hour's distillation to drive off all the water.

Paraffin cannot be substituted for xylol as it does not have a constant boilingpoint. This has been tested carefully, and at the end of an hour the boilingpoint has usually risen to $160^{\circ} \mathrm{C}$. and many of the tissues have begun to char. Glucose and starch are not affected by being distilled under xylol for a couple of hours, but cane sugar is and begins to char. In most cases it is sufficiently accurate to read off the volume of the water and take this as so many grams, but for more accurate determinations it is better to read off the scale, then empty the receiver completely and clean it. Then run in a little xylol and finally run in distilled water from a standard burette up to the previously observed scale mark. Then run the same volume of water from the same burette into a dry and weighed flask or weighing bottle and weigh again.

For larger animals the apparatus shown in the diagram (Fig. I $d$ ) is used. It consists of an ordinary Soxhlet extractor. This is first boiled out with xylol and the syphon tube is then sealed by putting a small amount of mercury in the extractor. The distillation is carried out as before, but the water which is 
condensed collects at the bottom of the extractor. When the distillation is complete and the apparatus has cooled down, both mercury and water and some of the xylol are run out by means of the tap at the bottom of the extractor into a suitable graduated cylinder or possibly a standard flask. For ordinary work the heights of the top of the mercury and the top of the water are read, but for accurate work only the height of the water under the xylol is read, and then the mercury, water and xylol are run out. The mercury is dried with acetone and warm air and returned to the clean dry graduated cylinder. Some clean xylol is added and then distilled water is run in from a standard burette as before.

The process has many advantages apart from the great saving of time. Volatile substances such as oils which would come off below the temperature of boiling xylol are absorbed by the xylol. If a gas such as $\mathrm{HCl}$ comes off as the result of dissociation of the calcium and magnesium chlorides, it does not cause a loss in weight, for it dissolves in the water and the water is determined in the first instance by volume and not by loss in weight.

I recently determined the percentage of water in the ordinary hen's egg by this method. The distillation took less than an hour and the result obtained was $65.4 \%$, which agrees closely with the figure given by Lebbin, $65.16 \%$ in I900 as quoted in Chemical Embryology by Needham (Cambridge, 193I). Doubtless the percentage of water in a hen's egg will vary with age, etc.

With a sponge the technique is slightly different, but it is quite simple. First of all a rather extensive set of experiments had to be carried out to determine what weight of distilled water is to be obtained when $100 \mathrm{~g}$. of the Plymouth Laboratory sea water is distilled under xylol by the method described above. The sea water in the tanks at Plymouth varies, but any serious alteration in its alkalinity is accompanied by a change in density, and this is automatically checked in finding the density or sinking factor of living aquatic organisms. Actually it was found that $100 \mathrm{~g}$. of the laboratory sea water, having a density of $\mathrm{I} .025 \mathrm{I} 8$ at a temperature of $19.0^{\circ} \mathrm{C}$., gave 96.8 (actually 96.796) g. of distilled water. This figure may or may not agree with the theoretical yield, but it includes the percentage experimental error which is far more important. The sponge is then weighed by the displacement method and returned to circulation for an hour. It is then transferred to the distillation flask, which has been weighed. If the sponge was known to weigh $50 \mathrm{~g}$. and the contents of the flask weighed I00 g., there would be $50 \mathrm{~g}$. of extraneous sea water present. If on distillation $80 \mathrm{~g}$. of distilled water was obtained, that from the sponge would be $80-48 \cdot 4 \mathrm{~g}$. Thus the percentage of water in a living sponge is found. In the modified Dean \& Stark method which requires the Soxhlet extractor some flasks had to be made with specially wide mouths and ground-glass adaptors, but otherwise the apparatus is again of a standard type.

In passing it may be well to note that the special method of distilling sea water is of some interest apart from anything else, for it is not possible by any known means to take sea water and evaporate it to dryness and obtain a 
constant weight of residue. Sea water always contains both calcium and magnesium chlorides, and as the water is driven off these will dissociate and continue to give off $\mathrm{HCl}$ till both the calcium and magnesium are present as $\mathrm{CaO}$ and $\mathrm{MgO}$. On distilling sea water below xylol a certain amount of dissociation always takes place and $\mathrm{HCl}$ is given off, but this makes no difference in the determination of the percentage of water, for as explained above the water is first measured by volume and not by weight. Contamination with xylol would in any case rule out the actual weighing of the water driven off.

\section{The Percentage of Silica AND Nitrogen}

On distilling the sponge Ficulina under xylol it does not disintegrate but retains its shape in a rather remarkable manner. The sponge can then be removed, the xylol burnt off and the whole heated to redness in a silica basin. The residue is then digested with strong nitric acid and the silica finally filtered off on a Gooch crucible which is heated to redness for several hours and then weighed. Thus the percentage of silica is obtained. Similarly a weighed amount of living sponge can be digested with sulphuric acid and potassium sulphate and the nitrogen estimated by Kjeldahl's method. Calcite can be estimated by several methods, but so far the percentage of carbon has not been determined successfully.

\section{Results OBTAINED With the DifFerent ORganisms}

\begin{tabular}{|c|c|c|c|c|c|}
\hline Sycon coronatum & $\begin{array}{l}\text { Density } \\
I \cdot 0925\end{array}$ & $\begin{array}{l}\text { Temp. } \\
{ }^{\circ} \text {. } \\
14 \cdot 6\end{array}$ & $\begin{array}{c}\text { Calcite } \\
\% \\
7.88 \\
\text { Silica }\end{array}$ & $\begin{array}{c}\text { Density of } \\
\text { protoplasm } \\
\mathrm{I} \cdot 0370\end{array}$ & $\begin{array}{c}\text { Water } \\
\% \\
\end{array}$ \\
\hline $\begin{array}{l}\text { Halichondria panicea } \\
\text { Ficulina ficus }\end{array}$ & $\begin{array}{l}\text { I.068 } \\
1.0809 \\
1.077 \\
1.0805 \\
1.0815\end{array}$ & $\begin{array}{l}\text { I5.0 } \\
\text { I } 5.6 \\
15.6 \\
\text { I6.5 } \\
17.0\end{array}$ & $\begin{array}{l}5.08 \\
3.85 \\
3.98 \\
5.506 \\
5.35\end{array}$ & $\begin{array}{l}\mathrm{I} \cdot 0384 \\
\mathrm{I} \cdot 057 \\
\mathrm{I} \cdot 056 \\
\mathrm{I} \cdot 049 \\
\mathrm{I} \cdot 0509\end{array}$ & $\begin{array}{l}\bar{Z} \\
8 \overline{1} \cdot 6 \\
80 \cdot 94\end{array}$ \\
\hline
\end{tabular}

The above figures were those obtained for a number of sponges, but unfortunately it was not possible at the time to substitute gravimetric estimations for titrations. It is obvious that there is a great deal of work to be done in this direction, but it is felt that it must be postponed till more material can be obtained and longer periods devoted to it.

G. P. Bidder realized many years ago that if the density of a living sponge could be obtained and the percentage of either calcite or silica present as spicules estimated, it should be possible to obtain a close approximation to the density of the protoplasm itself. This assumes that a sponge is composed of little else besides spicules and protoplasm. We know that a sponge consists of other things, but since it is unlikely that their density differs greatly from that of protoplasm the above assumption is reasonably valid. On this assumption the density of protoplasm has been computed, the method being the following: 


\section{Sycon coronatum (Ellis \& Solander)}

Temperature throughout: $14 \cdot 6^{\circ} \mathrm{C}$.

Distilled water (filling density bottle)

$50.9652 \mathrm{~g}$.

Sea water (filling density bottle)

$52 \cdot 3331 \mathrm{~g}$.

Sea water and sponge (filling density bottle)

$53.0210 \mathrm{~g}$.

\section{Volume determination}

Titrations I4.3I and II.40 ml. with $\mathrm{N} /$ ro silver nitrate

Vol. of sponge $=50.87-\left(\frac{I I \cdot 40}{I 4 \cdot 3 I} \times 50 \cdot 87\right)=10.345 \mathrm{ml}$.

Density of sea water $=\frac{52.3331 \times 0.999190}{50.9652}-\frac{0.0012(52.3331-50.9652)}{50.9652}=1.026055$.

Weight of water displaced by sponge $=10.345 \times 1 \cdot 0260=10.6145 \mathrm{~g}$.

Weight of water remaining in density bottle $=52 \cdot 333 \mathrm{I}-\mathrm{I0} \cdot 6 \mathrm{I} 45=4 \mathrm{I} \cdot 7 \mathrm{I} 86 \mathrm{~g}$.

Weight of living sponge

$=53 \cdot 02 \mathrm{IO}-4 \mathrm{I} \cdot 7 \mathrm{I} 86=\mathrm{II} \cdot 3024 \mathrm{~g}$.

Density of sponge $=\frac{I I \cdot 3024}{I 0 \cdot 345}=I \cdot 0925$

Weight of calcite $0.89 \mathrm{I} \mathrm{g}$.

Percentage of calcite $\quad 7 \cdot 88$

Weight of silica $\quad 0.035 \mathrm{I}$.

Density of calcite $=2 \cdot 72$.
Density of quartz $=2 \cdot 65$.

$W$, weight of living sponge; $M^{\prime \prime}$, weight of silica;

$M^{\prime}$, weight of calcite; $V$, volume of living sponge.

Density of protoplasm $=\frac{\mathrm{II} \cdot 3024-(0.89 \mathrm{I}+0.035)}{10.345-\left(\frac{0.89 \mathrm{I}}{2 \cdot 72}+\frac{0.035}{2 \cdot 65}\right)}=\mathrm{I} \cdot 037 \mathrm{I}=\mathrm{I} \cdot 037 \mathrm{I}$ at $\mathrm{I} 4 \cdot 6^{\circ} \mathrm{C}$.

I am greatly indebted to Dr Bidder for much advice and helpful criticism in connexion with these sponges.

Branchiopoda

Chirocephalus diaphanus Prévost

Artemia salina (Linn.)

Daphnia pulex (de Geer)

\section{CRUSTACEA}

Ostracoda

Candona candida O. F. Müller

Herpetocypris reptans Baird

$\begin{array}{rr}\begin{array}{r}\text { Temp. } \\ { }^{\circ} \text { C. }\end{array} & \begin{array}{c}\text { Sinking } \\ \text { factor }\end{array} \\ \text { II.3 } & \text { 10II } \\ 10 \cdot 0 & 988 \\ 7 \cdot 0 & 1017 \\ & \\ 7.6 & 1025 \\ 8.8 & 1170 \\ & \\ 15.4 & 1029 \\ 15.4 & 1033 \\ 16 \cdot 2 & 1014 \\ 8 \cdot 0 & 1023 \\ 15.6 & 1060 \\ & \\ 7.4 & 1045 \\ & \\ 20.0 & 1066 \\ 20.0 & 1088\end{array}$

Copepoda

Calanus finmarchicus (Gunnerus)

Anomalocera patersoni T"empleton

Diaptomus gracilis Sars

Tigriopus fulvus (Fischer)

1033

IOI4

1023

Leptostraca

Nebalia bipes (Fabr.)

1045

Amphipoda

Gammarus pulex de Geer

I066
I088 
Mysidacea

Hemimysis lamornae (Couch)

Temp. Sinking

${ }^{\circ} \mathrm{C}$. factor

6.4 1075

Decapoda

Leander serratus (Pennant)

Female (not in berry)

Female (not in berry) (highly coloured)

Female (in berry)

First larva

Palaemonetes varians (Leach)

Crangon vulgaris Lin".

Female (in berry)

First larva

,

$\begin{array}{cccc}\begin{array}{c}\text { Water } \\ \%\end{array} & \begin{array}{c}\text { Error by } \\ \text { direct } \\ \text { weighing } \%\end{array} & \begin{array}{c}\text { Temp. } \\ { }^{\circ} \mathrm{C} .\end{array} & \begin{array}{c}\text { Sinking } \\ \text { factor }\end{array} \\ 65 \cdot 08 & 73 \cdot 7 & 15 \cdot 2 & 1098 \cdot 4 \\ \overline{-} & - & 13 \cdot 8 & 1086 \\ 73 \cdot 14 & - & 15 \cdot 2 & 1066 \\ - & - & 15 \cdot 2 & 1068 \cdot 8 \\ - & - & 15 \cdot 2 & 1074 \\ - & - & 10 \cdot 8 & 1071 \\ - & - & 10 \cdot 8 & 1049 \\ - & - & 17 \cdot 2 & 1083 \\ - & - & 15 \cdot 5 & 1052 \\ - & - & 15 \cdot 5 & 1039\end{array}$

Homarus vulgaris Milne-Edwards.

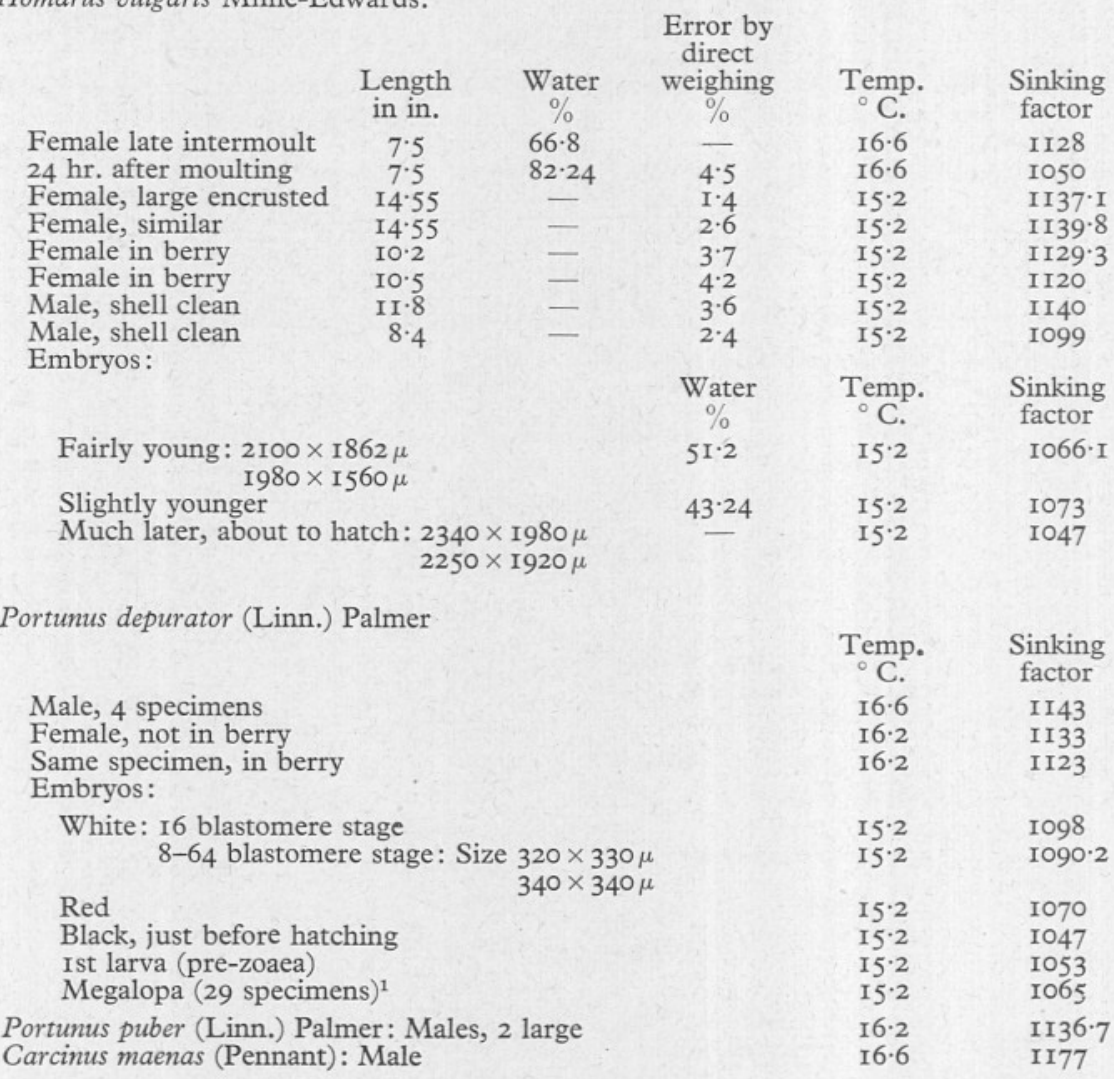

${ }^{1}$ Weight of a single specimen $0.0024 \mathrm{~g}$. 
Cancer pagurus Linn.

Female

Female

Female, 2 hr. after moulting

Female, same crab as above but I week later, abdomen still soft

Male

Male

Male

Male

Male

Width of
carapace
in $\mathrm{cm}$.

$$
\begin{gathered}
\text { Error by } \\
\text { direct } \\
\text { weighing } \\
\%
\end{gathered}
$$

$\begin{aligned} \begin{array}{r}\text { Temp. } \\ \text { C. }\end{array} & \begin{array}{c}\text { Sinking } \\ \text { factor }\end{array} \\ 5.6 & \text { I09I } \\ \text { I5.2 } & \text { II76 } \\ \text { I6.0 } & \text { I023.6 } \\ \text { I5.2 } & \text { I054 }\end{aligned}$

II $\cdot 2$ I

$20 \cdot 15$

10.68

I $2 \cdot 7$

$6 \cdot 8$

I0.13

10.5

I $5 \cdot 5$

23.75

15.2
5.6
5.6
5.6
15.2

I 2 I 8

III2

II 87

1230

1226

\section{FISH}

Conger vulgaris Cuvier $(27 \mathrm{~cm}$. long)

Gasterosteus aculeatus Linn.

Crenilabrus melops (L"inn.)

Lepadogaster bimaculatus (Donovan)

Pleuronectes platessa Linn., 5 small specimens

Cottus bubalis Euphrasén: Female

$$
\text { Male (water } 72.56 \% \text { ) }
$$

$\begin{array}{rl}\begin{array}{c}\text { Temp. } \\ \text { C. }\end{array} & \begin{array}{c}\text { Sinking } \\ \text { factor }\end{array} \\ \text { 10.0 } & \text { 1000 } \\ \text { 10.0 } & 1003 \\ 20 \cdot 0 & \text { I002 } \\ \text { I3.8 } & 1004 \cdot 5 \\ \text { I5.0 } & 1047 \\ 6 \cdot 8 & 1036 \cdot 3 \\ 6.4 & 1046 \\ 6.4 & 1054\end{array}$

\section{Scyllium catulus Cuvier (nursehound)}

Two young male specimens were obtained from the trawl. One (A) was weighed and then distilled under xylol and the percentage of water estimated, while the other (B) was kept alive in the aquarium and weighed at intervals. Another specimen (C) was a young female. There is apparently no means of telling the age of the Selachii. One large male was brought in to the laboratory having a weight (by direct weighing) of $5763 \mathrm{~g}$. and a length of II $2 \mathrm{~cm}$., while another weighed $4798 \mathrm{~g}$. and had a length of $105.4 \mathrm{~cm}$. By observing the growth rate of the small specimen (B) it was hoped to estimate the age of these larger fish, but unfortunately the death of the specimen after being kept alive for nearly I 8 months put an end to this work for the time being ${ }^{1}$. The following results were obtained:

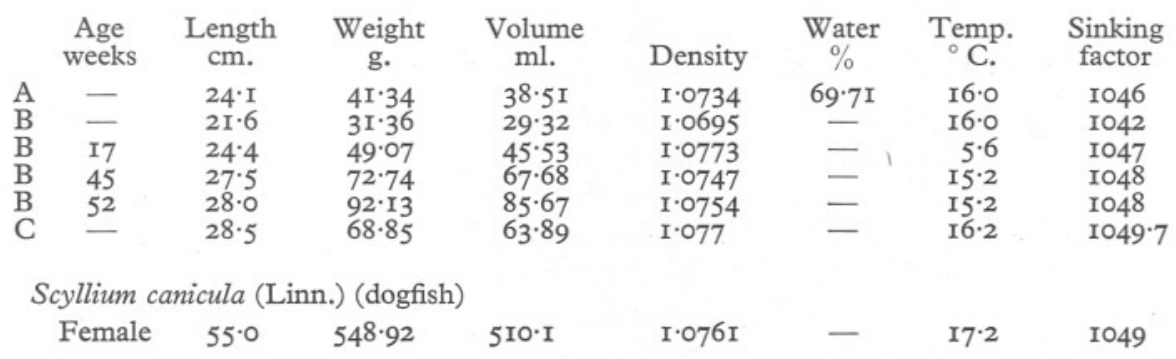

1 The figures under B show that after one year there had been the following changes:

Increase in length $29.5 \%$ Increase in volume $192.2 \%$ Increase in sinking factor $0.62 \%$
Increase in weight $193.8 \%$

Increase in density 0.55 


\section{MISCELLANEOUS}

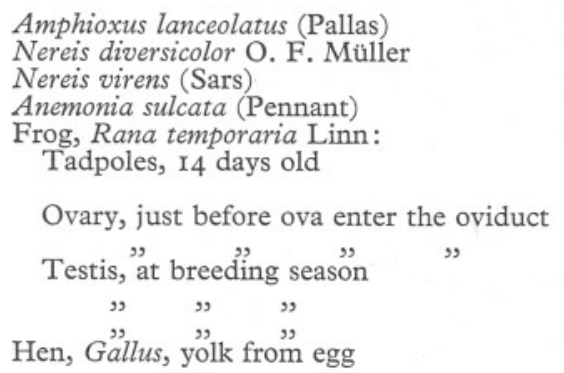

\begin{tabular}{|c|c|c|}
\hline$\underset{\%}{\text { Water }}$ & $\begin{array}{l}\text { Temp. } \\
{ }^{\circ} \text { C. }\end{array}$ & $\begin{array}{l}\text { Sinking } \\
\text { factor }\end{array}$ \\
\hline & $13 \cdot 2$ & I040 \\
\hline - & $7 \cdot 4$ & IO45 \\
\hline & $9 \cdot 6$ & 1033 \\
\hline $88 \cdot 19$ & $9 \cdot 5$ & 1017.6 \\
\hline - & $9 \cdot 6$ & $\begin{array}{c}\text { Ior } 4 \\
\text { Density }\end{array}$ \\
\hline - & $7 \cdot 4$ & $\mathrm{I} \cdot 0962$ \\
\hline & $\begin{array}{l}7.8 \\
8.0\end{array}$ & $\begin{array}{l}\mathrm{I} \cdot 0987 \\
\mathrm{I} \cdot 0506\end{array}$ \\
\hline & $9 \cdot 2$ & 1.0596 \\
\hline & 9.8 & 1.056 \\
\hline & 15.0 & $\mathrm{I} .0252$ \\
\hline
\end{tabular}

\section{Discussion OF RESULTS}

Direct Weighing

The displacement method of weighing an aquatic organism is a lengthy one, but there seems to be no alternative way of obtaining accurate results. I very much hoped that experiment would show that with the larger animals the error due to direct weighing, or weighing the animal wet on the balance, would be small and more or less constant; but this is not so. It would be possible to remove a great deal of the adhering water by the application of a cloth or filter paper, but this does not solve all the difficulties. By draining the animal for a definite time it is possible to keep the error on the one side, and certainly if the error were approximately constant much time could be saved; but the figures show that this is not possible. Thus, two large lobsters of the same length and neither of which was in berry gave widely different percentage errors with direct weighing. With smaller crustacea in berry the percentage error may be enormous. Reference to the figures will show that in a prawn in berry the error was nearly $74 \%$.

\section{Swimming}

An animal can only swim freely so long as it can support itself, and in all the organisms examined so far, with the exceptions of Artemia and the conger, a definite effort must be made by the animal to keep itself up. I have been able to make one determination only of the sinking factor of Artemia ; it appears that when it is swimming in strong brine, which is its normal habitat, it has to exert a muscular effort to keep itself below the surface. This state of affairs is not confined to Artemia, for in addition to many of the aquatic insects which take a supply of air below the surface of the water with them, the common stickleback, Gasterosteus aculeatus may be mentioned. This fish in fresh water has a sinking factor of 1002, which means that it must make an effort to keep itself off the bottom. Frequently the fish can be seen resting on the bottom, and it often feeds on crustacea, many of which have a high sinking factor. I have observed this fish after a big feed of ostracods unable to lift itself up at 
all. The stickleback can also be transferred suddenly from fresh water to sea water without any apparent injury, and this means that for a period the fish is less dense than its environment or in other words its sinking factor is less than Iooo. I have observed that when treated in this manner the fish exert a great deal of energy in keeping themselves down, and it takes about $6 \mathrm{hr}$. before they are again capable of resting on the bottom.

The amount of work which must be done by a fish to keep itself off the bottom must depend on its sinking factor and, as stated above, if this is rooo no effort is required. It is possible to show on theoretical grounds that it is not possible for an aquatic organism to remain in a state of hydrostatic equilibrium with its environment; but it appears that in the conger the difference between its density and that of its environment is less than I part per Iooo.

The limitation of cilia as organs of locomotion was pointed out by Gray in I928 (Ciliary Movement, Camb. Univ. Press), and it should be clear that cilia can only sustain and propel an organism provided its sinking factor is below a certain figure. What that figure is remains to be determined. The first larvae of echinoderms certainly have a low sinking factor and this is true of trochophores, but I look forward with great interest to finding the highest sinking factor attained by free-swimming veligers or the later larvae of echinoderms or any organism supported by cilia alone. What has been said about cilia is also true of limbs or other appendages moved by muscles. So far as fish are concerned it appears that the limit has been attained by the dogfish or nursehound, and the figure appears to be very close to 1050; but it must be remembered that the method of obtaining the correct sinking factor has only just been perfected. Few figures are available for dogfish, and at present living dogfish cannot be obtained at Plymouth. No determinations for the skates or rays have yet been made, but it is interesting to note that the sinking factor of such teleosts as the young plaice, Lepadogaster and Cottus, which only swim with difficulty, is below that of the free-swimming dogfish.

With crustacea the sinking factor attains a far higher figure. I098 has been recorded for the prawn, Leander, which normally swims by means of its pleopods, while II4O has been obtained for the lobster, an animal which is certainly capable of raising itself off the bottom even if it does not actually swim. Portunus reaches an even higher figure, II 43 , but neither of the two animals last mentioned can be described as pelagic, and it is doubtful if this term can be applied to prawns or shrimps which spend a great deal of their time resting on the bottom. Truly pelagic malacostraca are difficult to secure, especially at the present time, but they will probably be found in due course among the euphausids or mysids. It is interesting to note that Hemimysis lamornae has a sinking factor of 1075, while that of the first larva of the prawn, which is certainly pelagic, $1 \mathrm{~s}$ I074.

A point of considerable interest arises with regard to crustacea in berry, and the work may throw considerable light on the habit of carrying the eggs or embryos which is so prevalent among the crustacea. At first sight it would 
appear that the female is considerably hampered by having to carry this extra load, but this does not really represent the actual fact. In all the cases so far investigated the embryos have a sinking factor which is less than that of the adult and, thus, while a prawn in berry does actually weigh more than one not in berry, yet her sinking factor in berry is less than when she is out of berry. The load of eggs or embryos may impede her rate of swimming, but it has the compensating effect of causing her to make less effort to keep herself afloat. Thus it may be an advantage rather than otherwise for the female to carry her young. This, however, cannot be the cause of her doing so, for the far heavier crabs, which are quite incapable of swimming, also carry their eggs.

Reference to the figures on p. 568 will show that the sinking factor of the crustacean eggs and embryos is high. Cilia do not occur in the crustacea, but if they were to be found we should expect them first to occur in the early embryonic stages. The segmentation in the early stages of Portunus depurator is equal and holoblastic and the blastulae appear to be as symmetrical in their formation as those of Echinus esculentus. They are, however, much larger and never become free swimming by means of cilia; their sinking factor is in fact so high that they could not in any event be supported by cilia. It is true that the early embryos of Portunus depurator are considerably larger than those of Echinus esculentus, but the embryos of such organisms as Cyclops and Diaptomus are much smaller than many of the ciliophora or the flagellated organisms like Volvox globator. It appears then that there is something in the crustacean embryos which makes them abnormally heavy, but what this substance is apparently remains to be investigated.

Statements are made in many standard text-books that the density of the ovum in general is determined by the amount of yolk it contains, a large amount of yolk causing a high density. This, however, is incorrect, for the density of the yolk of the ordinary hen's egg has been obtained and found to be $\mathrm{I} .0252$ at $15^{\circ} \mathrm{C}$., which agrees fairly well with the figure given by Baudrimont \& de St Ange (I846), as quoted by Needham in Chemical Embryology, namely, $\mathrm{I} \cdot 0288-\mathrm{I} \cdot 0299$. This means that if the yolk of the crustacean egg is in any way comparable to that of the hen a large amount of yolk should decrease the density or lessen the sinking factor, since the density of the yolk of the hen's egg is less than that of Plymouth sea water and less than that of protoplasm itself.

The density of the cytoplasm of the eggs of Arbacia according to Heilbrunn as quoted by Gray (Experimental Cytology, Cambridge, I93I, p. 63) is I.03583. This is lower than the lowest figure which I obtained for the density of protoplasm in sponges, but even so it is higher than the density of yolk. Reference to Heilbrunn's paper reveals to my mind a rather serious objection, for to quote Gray: 'The specific gravity of the granules was determined by shaking the eggs to pieces; the resultant suspension was then centrifuged into sugar solutions of varying specific gravity to find a solution in which the granules just pass to the bottom of the solution.' But solutions of sugar which vary in 
density must also vary in osmotic pressure. A hypertonic solution of sugar would withdraw the lightest substance in the granules, namely, water. This point seems to have been overlooked.

The eggs ${ }^{1}$ of Portunus depurator and Homarus vulgaris appear to be very dense to begin with, and the sinking factor gradually becomes less and less, probably due to the absorption of water, till they assume a sinking factor of about I050. At this stage the larvae become free, with a sinking factor of practically the same figure, and muscular limb movement readily supports them.

In passing it is interesting to note that the sinking factor of Calanus is so low that it is probably lower than that of its embryos. It is also an organism which undergoes extensive vertical migrations, and it therefore appears to be significant that the eggs are not carried by the female, at any rate in the later stages.

Nearly all the work on crustacea is, however, hampered by their undergoing ecdysis. A crab just after moulting had a sinking factor of I023, while a week later its sinking factor was I054. Months later it would attain a figure of I230 according to the data already recorded, and until there is some means of ascertaining the state of the intermoult the use of the figures for the sinking factor is somewhat restricted. It seems that a rather laborious piece of work is indicated, namely, that of isolating a number of crustacea and weighing each individual periodically. An attempt was made to ascertain how far the sinking factor of Palaemonetes varians was effected by its migrating from sea water into brackish water; but the experiment consisted merely of finding the sinking factor of some individuals kept in brackish water and comparing it with data from those kept in sea water. The figures showed nothing and clearly any change would be masked by variation due to the state of the intermoult. An adult female freshwater crayfish, Potamobius pallipes, was investigated and compared with a young female lobster, neither being in berry. The result is given below, but it is doubtful whether it means very much at present.

$$
\begin{array}{lcc} 
& \text { Crayfish, adult female } & \text { Lobster, length } 7.5 \text { in. } \\
\text { Sinking factor } & \text { II30 } & \text { I I } 28 \\
\text { Water } & 7 \mathrm{I} .05 \% & 66.68 \%
\end{array}
$$

The highest figure reached by any freely moving animal is 1230 for the crab, Cancer pagurus, with a width of carapace of $15.5 \mathrm{~cm}$. It is interesting to note that a much larger specimen with a width of carapace of $23.75 \mathrm{~cm}$. gave 1226 , while a much smaller specimen with a width of carapace of only $6.8 \mathrm{~cm}$. gave I218. The crabs appear to have higher sinking factors than the lobsters, but in spite of this they seem to have attained far greater activity on land.

No attempt will be made to discuss the function of the so-called swimbladder of the teleost fishes; it is a fact that those fishes with a swim-bladder have a low sinking factor while those without it have a high one. Reference to the figures will show that the sinking factor of adult dogfishes and nursehounds appears to be remarkably constant, namely, $1050 \pm \mathrm{I}$.

1 The word egg, though it is the one in general use, should really be replaced by embryo. 


\section{The Effect of Spines in Crustacea}

A very noticeable characteristic of many of the pelagic crustacea, both fresh water and marine, is the outgrowth of the integument in the form of spines or setae, and the function of these has been the subject of a good deal of discussion. By some they are supposed to have a buoyancy effect, while it has also been suggested that their effect is to maintain or restore the centre of gravity of the organism to a certain position. Clearly the term buoyancy cannot be used of an organ or tissue which has a greater density than that of the environment, and the term should be restricted to such structures as bladders containing gas or possibly to oil-drops. I have discussed the effect of these spines on the centre of gravity in a previous communication and given my reasons for considering this theory untenable (Lowndes, A. G., Proc. Linn. Soc. London, Ses. 150, 1937-38, 25 March 1938, pp. 62-73). The chief effect of these spines is to slow down the rate of sinking. Spines and setae can have another effect however, for it is known that pelagic crustacea such as Calanus and Diaptomus as well as the nauplius and many decapod larvae have a slow gliding method of propulsion to which is added a sudden leaping or escape movement. Calanus itself when quiescent remains with its antennules extended and its body practically vertical. The sudden leap due to the action of the thoracic limbs which are otherwise motionless causes the animal to dart away suddenly in a plane at right angles to the vertical. If it darted off in the vertical direction when it was near the surface it would clearly leap out of the water (this actually happens in Anemalocera patersoni). Calanus is able to hang vertically by means of the long and characteristic plumose setae on the antennules. The effect of these setae thus is to cause the animal to sink slowly and in the most advantageous position so far as its escape movement is concerned.

\section{SUMMARY}

The method by which the weight, volume, density and sinking factor of living aquatic organisms can be determined has been extended. By sinking factor is meant the ratio of the density of the organism to that of its environment at the time of the actual determination. The density of the environment is always raised to Iooo, and the density of the organisms computed on this basis.

A quick and accurate method for determining the percentage of water in a living organism has been described and discussed.

On the assumption that a sponge consists of protoplasm and spicules only, the density of the protoplasm has been computed.

The sinking factor of several fish and of the embryos of some crustacea at different stages has been determined. One effect of the swim-bladder in teleost fishes is to reduce the sinking factor and thus facilitate swimming.

The effect of the sinking factor on swimming in general and the effects of spinous outgrowths in pelagic crustacea are discussed. 